\title{
Bertholletia excelsa Humboldt \& Bonpland (Lecythidaceae): aspectos morfológicos do fruto, da semente e da plântula ${ }^{1}$ \\ Bertholletia excelsa Humboldt \& Bonpland (Lecythidaceae): morphological aspects of fruit, seed and seedling
}

\author{
João Ubiratan Moreira dos Santos ${ }^{1}$ \\ Maria de Nazaré do Carmo Bastos ${ }^{1}$ \\ Ely Simone Cajueiro Gurgel ${ }^{1}$ \\ Ana Cristina Magalhães Carvalho ${ }^{\text {II }}$
}

\begin{abstract}
Resumo: Bertholletia excelsa Humboldt \& Bonpland, conhecida popularmente como castanha-do-pará e castanha-do-brasil, é uma árvore que pode atingir até $50 \mathrm{~m}$, ocorre em toda a região amazônica, sendo característica das matas altas de terra firme não inundáveis. Suas castanhas ou sementes são muito apreciadas, internacionalmente conhecidas, constituindo um dos principais produtos de exportação da Amazônia. Objetivou-se, com este estudo, descrever a morfologia do fruto, da semente e da plântula da referida espécie, utilizando-se 30 frutos, 30 sementes e 10 plântulas. Registrou-se, dos frutos, a morfologia geral, a coloração, a textura, a consistência, a deiscência e o indumento; das sementes, o tegumento e o embrião, bem como os principais elementos vegetativos das plântulas. Considerou-se plântula a fase de desenvolvimento em que os eófilos estavam totalmente formados. Fundamentou-se todo o estudo em literatura especializada e ilustraram-se os principais caracteres morfológicos com fotografias. A espécie estudada apresenta fruto simples, do tipo cápsula poricida, indeiscente, bisseriado, pedúnculo opaco, em tons castanhos, superfície glabra e fibrosa; pericarpo castanho escuro, opaco, crustáceo, glabro, levemente fibroso e septado; funículo em tons castanhos e lenhoso. Semente triangular angulosa axilar e estenospérmica; testa castanho claro, superfície opaca, rugosa e glabra e de consistência lígnea; rafe em tons castanho escuros, rígida e saliente, hilo oblongo e em depressão; embrião conferruminado. Germinação criptocotiledonar hipógea. Plântula com eófilos simples, alternos, obovóides, ápice agudo, margem serreada e castanha avermelhada, base simétrica e atenuada, peninérveos, craspedródomos e prefolheação revoluta; hipocótilo ausente; epicótilo epígeo, cilídrico, lenticelado, com muitos catáfilos triangulares e lanceolados.
\end{abstract}

Palavras-chave: Manejo florestal. Silvicultura. Identificação de plântulas. Amazônia.

\footnotetext{
I Museu Paraense Emílio Goeldi. Cordenação de Botânica. Belém, Pará, Brasil (bira@museu-goeldi.br) (nazir@museu-goeldi.br) (esgurgel@museu-goeldi.br).

II Museu Paraense Emílio Goeldi. Cordenação de Botânica. Bolsista de Desenvolvimento Tecnológico Industrial / CNPq. Belém, Pará, Brasil(anitacarval@yahoo.br).

1 Embrapa Amazônia Oriental / Projeto Dendrogene (Conservação Genética nas Florestas Manejadas da Amazônia / DFID).
}

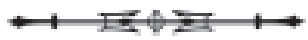


Abstract: Bertholletia excelsa Humboldt \& Bonpland is a tree that can reach up to $50 \mathrm{~m}$, known popularly as brazilian nut and castanha-do-pará, it happens in the whole Amazonian area; characteristic of the high forests, their nuts or seeds are very appreciated. Being known internationally, they constitute one of the main products of export of the Amazonian. It was aimed, at with this study, to describe the morphology of the fruit, of the seed and of the seedlings of the referred species; being used 30 fruits, 30 seeds and 10 seedlings. Enrolled the general morphology, the coloration, the texture, the consistence, the dehiscence and the indument of the fruits; of the seeds the tegument and the embryo, as well as the main vegetative elements of the seedlings. Was considered seedlings the development phase in that the first two eophylls were totally formed. The whole study was based in specialized literature and the main morphologic characters were illustrated with pictures. The studied species presents simple fruit, of the type poricidal capsule, in dehiscent, biseriate, opaque stalk, in brown tones, surface glabrous and fibrous; dark, opaque brown pericarp, crustacean, glabrous, slightly fibrous and septate; funiculus woody and in brown tones. Angular triangular seed axillary and estenospermic; tests clear brown, surface opaque, wrinkled and glabrous and of ligneous consistence; raphein tones chestnut tree darkness, rigid and salient, hilum oblong and in depression; embryo conferruminated. Gerrmination cryptocotylar hypogeous. Seedlings with simple eophylls, alternating, obovate, acute apex, margin serrate and brownish red, base symmetrical and attenuated, penniveined, broquidodromus and prevernal involute; hypocotyl is absent; epicotyl epigeous, orbicular, lenticeled, with many triangular cataphylls lanceolate and alternated.

Keywords: Forestry management. Silviculture. Seedlings identification. Amazon. 


\section{INTRODUÇÃO}

As Lecythidaceae Neotropicais abrangem 197 espécies descritas em 11 gêneros (PRANCE; MORI, 1979). A espécie mais conhecida, principalmente pela importância econômica, é Bertholletia excelsa Humboldt \& Bonpland.

Bertholletia excelsa tem vários nomes populares: castanheira, castanha-do-brasil, eraí(índios Caruchis), iniá (índios Chipayas) e tocary (índios Parecis) (LOUREIRO, 1979); Brazil nut, Pará nut(inglês), noix du Brésil, noix de Pará, chatãigne du Brésil (francês), nuez del Brasil (espanhol), paranuss (alemão) e noce del Brasilie (italiano) (CAVALCANTE, 1996).

São árvores de grande porte, vez que na fase adulta podem atingir mais de $60 \mathrm{~m}$ de altura e a base do tronco pode alcançar mais de $4 \mathrm{~m}$ de diâmetro. $\mathrm{A}$ castanheira-do-pará desenvolve-se em regiões de clima quente e úmido, situadas nas áreas de terra firme, em solos argilosos ou argilo-arenosos, podendo, também, ocorrer em concrecionário laterítico (piçarra) (MÜLLER, 1995).

É uma árvore social, encontrando-se em grupamentos mais ou menos extensos, conhecidos como castanhais, associadas a outras espécies florestais de grande porte (CAVALCANTE, 1996).

As amêndoas (embriões) possuem grande valor industrial, extraindo-se delas cerca de $67 \%$ de óleo claro, inodoro, insípido, comestível quando fresco, sendo excelente para saboaria fina. O líber da casca fornece uma estopa excelente e fibras para cordoaria (LE COINTE, 1947).

Possui também alto valor protéico devido à quantidade e à qualidade dos aminoácidos contidos nas amêndoas. $\bigcirc$ ouriço, após a retirada das sementes, é usado na confecção de peças de artesanato ou como combustível, notadamente, para a defumação da borracha. Ao lado de outras essências florestais, é excelente alternativa para reflorestamento de áreas degradadas de pastagens ou de cultivos anuais, tanto para a produção de frutos como para a extração de madeira (MÜLLER, 1995).
A madeira, apesar de muito boa para forros, paredes e soalhos, não tem uso constante devido a seus frutos possuírem maior valor comercial (SILVA; LISBOA P.; LISBOA S., 1977), e em razão de estar protegida por lei ambiental que impede sua comercialização.

Segundo Moritz (1984), do início do desenvolvimento dos frutos à maturação decorrem cerca de quinze meses, podendo ser encontrados frutos da safra passada com os ainda imaturos; além disso, ressalta-se, no mesmo trabalho, que os frutos são pixídios arredondados, denominados ouriços, cujas sementes não são nozes (castanhas), mas sim caroços de um pixidio; que a casca do ouriço, o pericarpo, é dura e resistente; e as sementes estão unidas, através do funículo.

Mori e Prance (1990) fazem uma descrição e uma ilustração simples da plântula, citando a ausência de cotilédones e um embrião sem diferenciação remanescente no interior dos tegumentos. Os dados publicados neste trabalho podem ser considerados complementares aos desses autores.

Este estudo objetivou descrever e caracterizar a morfologia do fruto, da semente, tipo de germinação e a plântula de Bertholletia excelsa Humboldt \& Bonpland, visando a subsidiar o seu reconhecimento (identificação) nas formações naturais e o seu manejo, bem como embasar futuros trabalhos taxonômicos, filogenéticos e ecológicos referentes à espécie em estudo.

\section{MATERIAL E MÉTODOS}

Coletaram-se frutos maduros, diretamente da copa e no chão sob a matriz, de um espécime existente no campus de pesquisas da Embrapa Amazônia Oriental, Belém, Pará.

Procedeu-se a coleta de material botânico fértil para confecção de exsicatas e identificação. As exsicatas da planta matriz foram incorporadas aos herbários sob os números IAN 176.901 e MG 168.265 (Gurgel, E.S.C. 123).

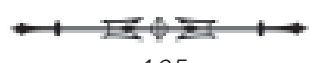


O material foi transportado para o laboratório de Botânica da Embrapa Amazônia Oriental, onde os frutos e as sementes foram beneficiados até a completa limpeza.

Uma subamostra com 30 frutos e 30 sementes foi retirada aleatoriamente para a descrição morfológica. Dos frutos, registrou-se a morfologia geral, classificação, coloração, textura, consistência, posição, a deiscência e o indumento do pericarpo; da semente, analisou-se o tegumento, o endosperma e o embrião. Quanto aos caracteres morfológicos da semente, foram analisados a forma e borda, a consistência, cor e textura dos tegumentos, posição do hilo e da micrópila e o embrião no que tange ao tipo e forma.

Considerou-se germinação o período entre o entumescimento da semente até antes que os eófilos estivessem totalmente formados; e plântula, a fase de desenvolvimento em que os eófilos estavam totalmente formados. A definição de eófilo e metáfilo foi feita com base na análise da planta matriz, levando-se em consideração o conceito de Duke e Polhill (1981). Para o processo germinativo e para a morfologia da plântula utilizou-se vermiculita em bandeja de plástico com $80 \times 40 \times 20 \mathrm{~cm}$.

A metodologia e a terminologia empregadas estão de acordo com os trabalhos de Martin (1946), Systematics Association Committee for Descriptive Terminology (1962), Font-Quer (1965), Duke (1965, 1969), Van der Pijl (1972), Radford et al. (1974), Kuniyoshi (1983), Roderjan (1983), Van Roosmalem (1985), Stern (1992), Oliveira (1993), Barroso et al. (1999) e Gurgel (2000).

Os frutos, as sementes e as fases do desenvolvimento, desde a emissão da radícula até a completa formação dos eófilos, foram fotografados. O material vegetativo, relacionado ao processo germinativo e às plântulas, foram desidratados em estufa para posterior confecção de exsicatas, com as suas respectivas etiquetas. As amostras foram incorporadas sob os números MG 168.204 (Gurgel, E.S.C. 162) e IAN 178.340 (Carvalho, A.C.M., 90).
Os caracteres morfológicos dos frutos e sementes, do processo germinativo e das plântulas foram ilustrados com fotografias, feitas em lupa Zeiss Stemi SV6, com capturador de imagem digital sound vision SV micro adaptado, e máquina fotográfica digital Nikon DIX, com lentes para aumentar as estruturas.

\section{RESULTADOS}

\section{Morfologia do fruto}

Cápsula poricida simples, indeiscente, orbicular, levemente achatada, em corte transversal apresentase arredondada, não estipitada (Figura 1a). Pedúnculo em tons castanhos, homócromo, opaco, glabro, com retículos transversais. Fruto estenocárpico, subgloboso (Tabela 1). Quando imaturo o fruto apresenta um exudato na região de inserção do fruto com o pedúnculo (Figura 1b). Exocarpo castanho escuro, opaco, reticulado, com lenticelas estouradas, glabro, fibroso e com 0,993 cm de espessura (Figura 1c e 1d); mesocarpo castanho claro, homócromo, mais espesso que o exocarpo $(2,422 \mathrm{~cm})$, glabro, fibroso (Figura 1e); endocarpo castanho escuro, semelhante ao exocarpo, opaco, rugoso, glabro, cartáceo, levemente fibroso e septado. Funículo lenhoso, em tons castanho e glabro.

\section{Morfologia da semente}

Descrição externa: estenospérmica; triangular angulosa; trisseriada; base, margem e ápice angulosos (Figura 2a). Constituída por duas camadas de tegumento, a testa, mais externa, em tons castanho claros, opaca, rugosa, glabra e lígnea, com linhas de fratura por toda a sua extensão (Figura 2a e 2d); a camada mais interna, o tégmen, é membranoso e castanho mais escuro que a testa (Figura 2b). Hilo em depressão, subapical, grande, oblongo, castanho mais claro que a testa, rafe rígida e saliente, em tons castanhos escuros e homócroma (Figura 2a) (Tabela 2).

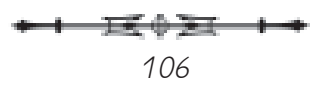




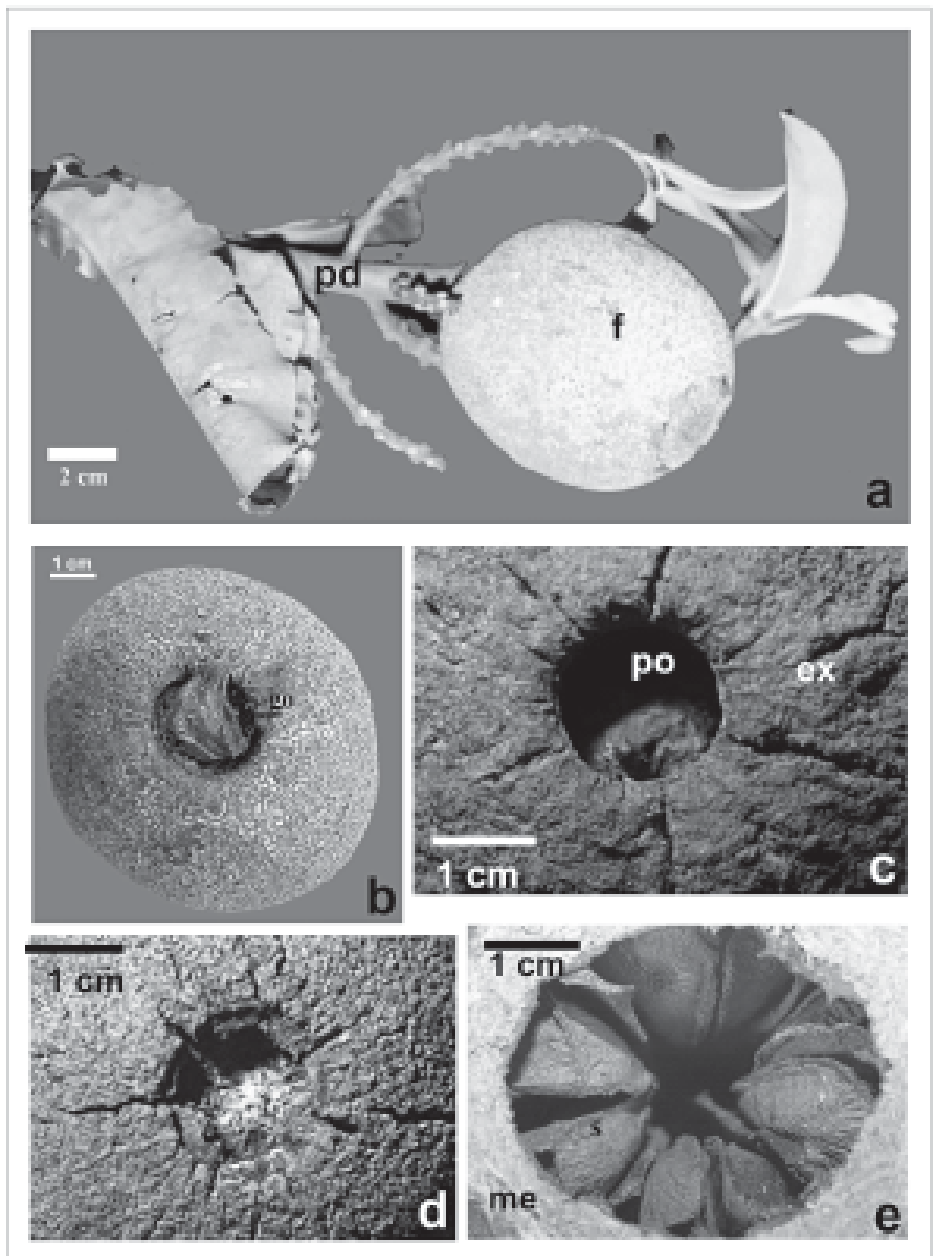

Figura 1. Bertholletia excelsa Humboldt \& Bonpland. Detalhes do fruto.: a) hábito do fruto imatur; b) base do fruto imaturo; c) ápice da cápsula poricida; d) base da cápsula poricida; e) secção transversal do fruto. ex-exocarpo; f-fruto; go-goma; me-mesocarpo; pdpedúnculo; po-poro; s-semente.

Tabela 1. Dimensões (cm), desvio padrão e coeficiente de variação (C.V.) dos frutos de Bertholletia excelsa.

\begin{tabular}{llllll}
\hline & Máximo & Média & Mínimo & Desvio Padrão & C.V. (\%) \\
\hline Comprimento & 11,096 & 9,614 & 8,069 & 0,848 & 9,549 \\
Diâmetro maior & 11,147 & 9,755 & 7,833 & 0,803 & 8,018 \\
Diâmetro menor & 10,242 & 9,451 & 7,544 & 0,622 & 6,464 \\
\hline
\end{tabular}

Tabela 2. Dimensões (mm), desvio padrão e coeficiente de variação (C.V.) das sementes de Bertholletia excelsa.

\begin{tabular}{llllll}
\hline & Máximo & Média & Mínimo & Desvio Padrão & C.V. (\%) \\
\hline Comprimento & 55,56 & 45,86 & 18,04 & 7,76 & 16,93 \\
Diâmetro maior & 33,43 & 28,12 & 21,95 & 2,97 & 10,55 \\
Diâmetro menor & 25,76 & 20,20 & 14,15 & 3,23 & 16,02 \\
\hline
\end{tabular}


Descrição interna: embrião atípico, triangular, conferruminado, não havendo distinção de cotilédones, eixo hipocótilo-radícula e plúmula (Figura 2c e 2d).

\section{Morfologia da germinação}

Criptocotiledonar, hipógea e com emergência reta (Figura 3b). Aproximadamente 10 meses depois, a semente (Figura 3a) começa a germinar; inicialmente, a radícula, em corte transversal, é arredondada, branca amarelada, crassa, glabra, medindo 5,21 ×1,09 mm. Após 30 dias, com o decorrer do alongamento, mede 47,61 mm, é mais espessa e não apresenta modificações quanto às outras características (Figura 3c). Coifa e coleto são imperceptíveis (Figura 3c). Observa-se a presença de catáfilos alternos (Figura 3 e) em toda a extensão do epicótilo.

\section{Morfologia da plântula}

Sistema radicular embrionário, raiz principal cilíndrica, base mais espessa que a região mediana, que é mais espessa que o ápice, apresenta cor castanha, sublenhosa e glabra; raízes secundárias presentes em pequena quantidade, filiformes, castanhas, sublenhosas e glabras (Figura 4a). Colo, hipocótilo e cotilédones imperceptíveis (Figura 4a). Epicótilo epígeo, ilíndrico, no ápice da semente, base em tons castanhos com muitas lenticelas estouradas, da região mediana até o ápice apresenta-se castanho arroxeado (viridiscente). Catáfilos triangulares, arroxeados, alternos e pilosos (Figura 4a). Eófilo um simples, obovóide, prefolheação involuta (Figura 4b), nervação broquidódroma (Figura 4c), com nervuras imersas na face adaxial (Figura 4d) e impressas na face abaxial, ápice agudo, margem levemente

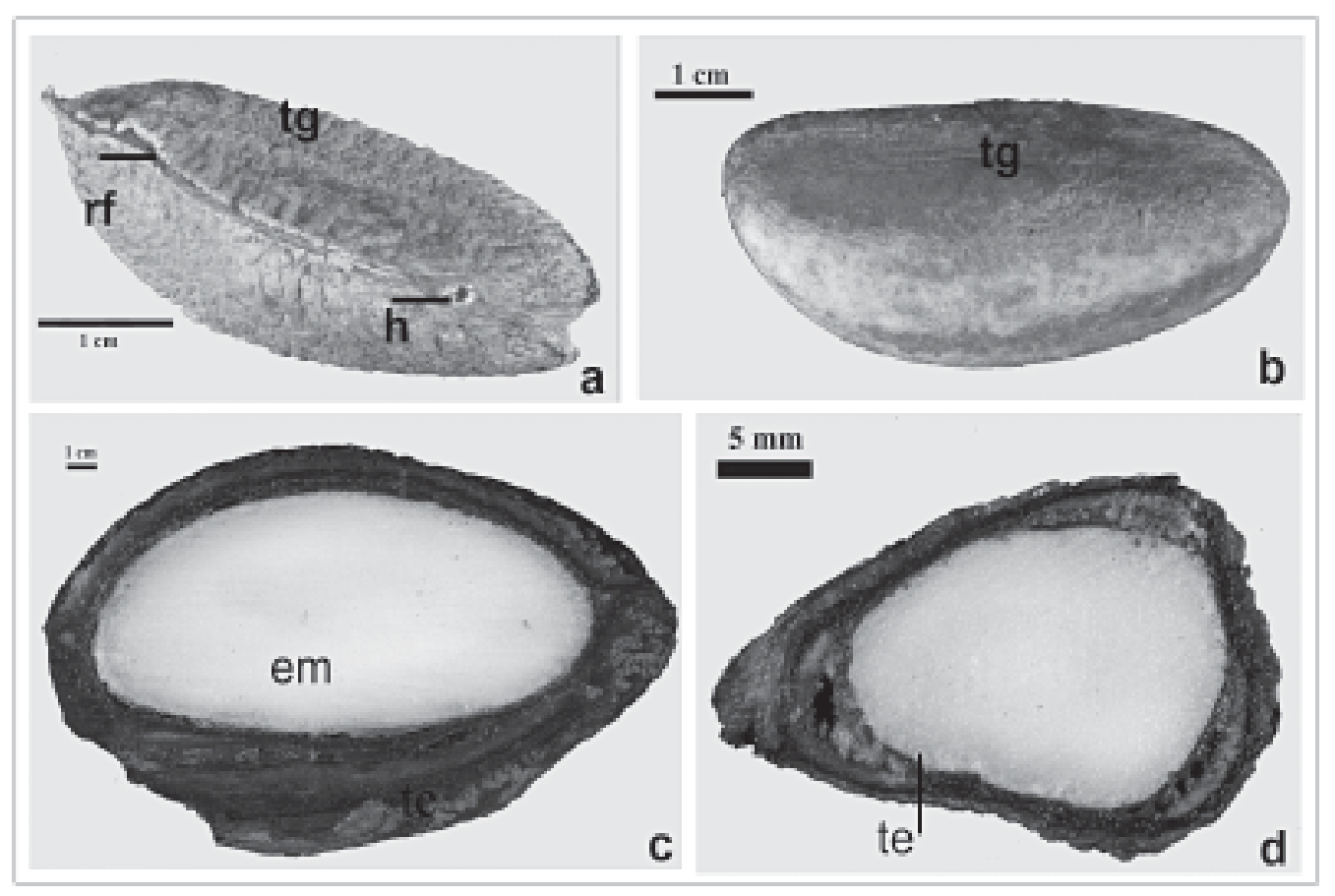

Figura 2. Bertholletia excelsa Humboldt \& Bonpland. Detalhes da semente: a) semente inteira em vista hilar; b) embrião; c) secção longitudinal do embrião conferruminado; d) secção transversal do embrião. h-hilo; rf-rafe, te-testa, tg-tégmen, em-embrião.

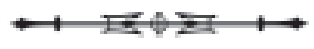




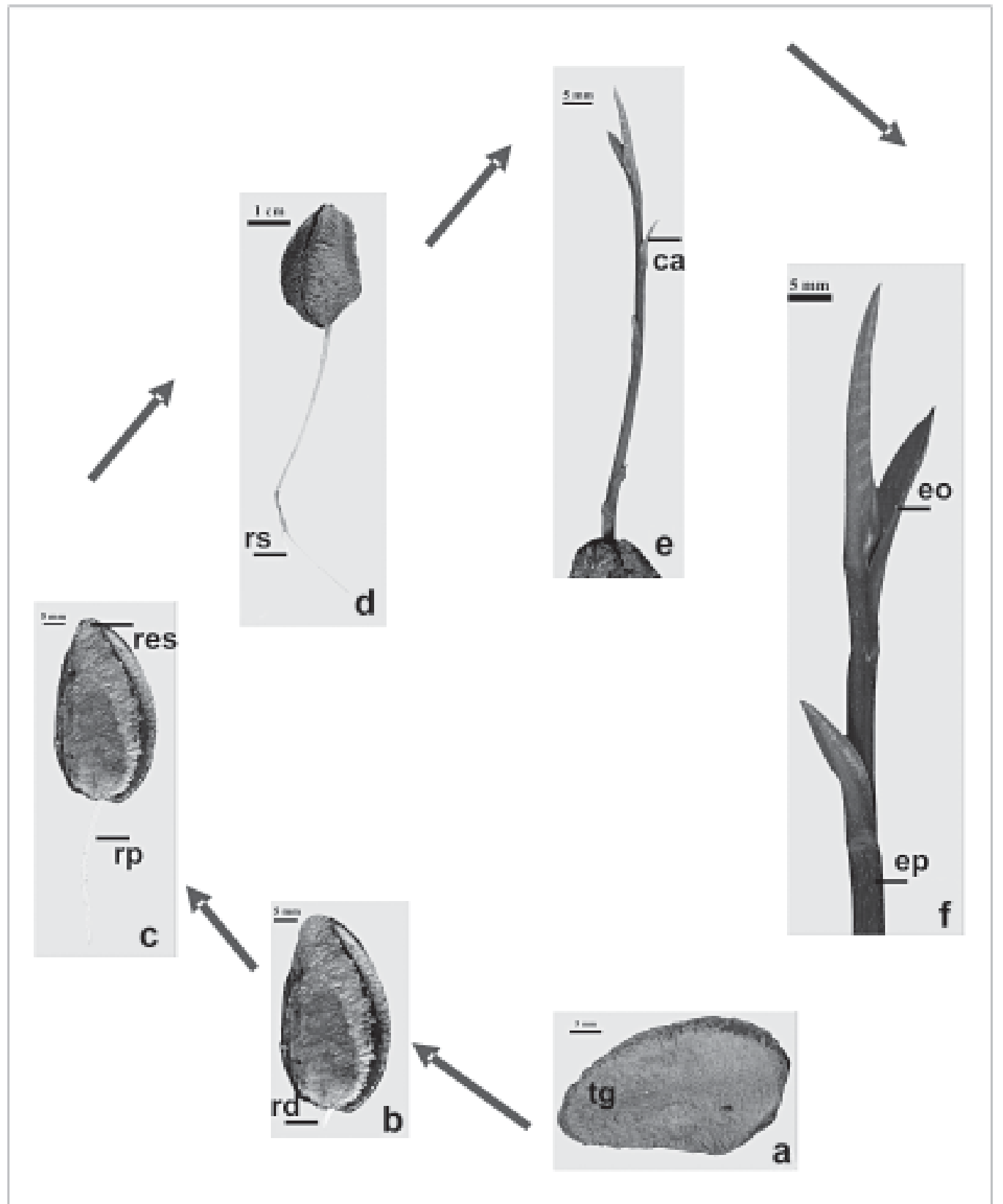

Figura 3. Bertholletia excelsa Humboldt \& Bonpland. Detalhes do processo germinativo: a) semente inteira; b) radícula, 10 meses após a semeadura; c) raiz primária alongada, 10 meses e 7 dias; d) raiz secundária, 11 meses; e) catáfilos alternos, 12 meses; f) início da prefolheação dos eófilos 13 meses. ca-catáfilo; eo-eófilo; ep-epicótilo; res-restos seminais; rp-raiz primária; rs-raiz secundária; tg-tegumento.

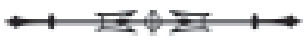


serreada em tons castanho avermelhados, base simétrica e atenuada; pecíolo levemente canaliculado e subséssil, pulvino ausentes. Segundo eófilo um, semelhante ao primeiro, com filotaxia alterna em relação ao mesmo (Figura 4b).

\section{DISCUSSÃO E CONCLUSÃO}

Cavalcante (1996) refere-se ao fruto de Bertholletia excelsa como uma cápsula do tipo pixídio incompleto. Müller (1995) classifica-o como cápsula indeiscente, ou seja, que não se abre espontaneamente. Oliveira e Daly (2001) classificam o fruto da castanha-do-pará como secundariamente indeiscente, devido ao diâmetro da abertura do fruto ser menor que o diâmetro da semente.

Segundo Barroso et al. (1999), o fruto de Bertholletia é uma cápsula poricida, originado de ovário súpero, com dois ou mais carpelos, cuja deiscência dá-se por meio de poros, porém, nem todos os frutos desse tipo liberam as sementes através dessas aberturas, a exemplo de Bertholletia, cujo orifício do pericarpo não possui dimensões suficientes para permitir a saída da semente.

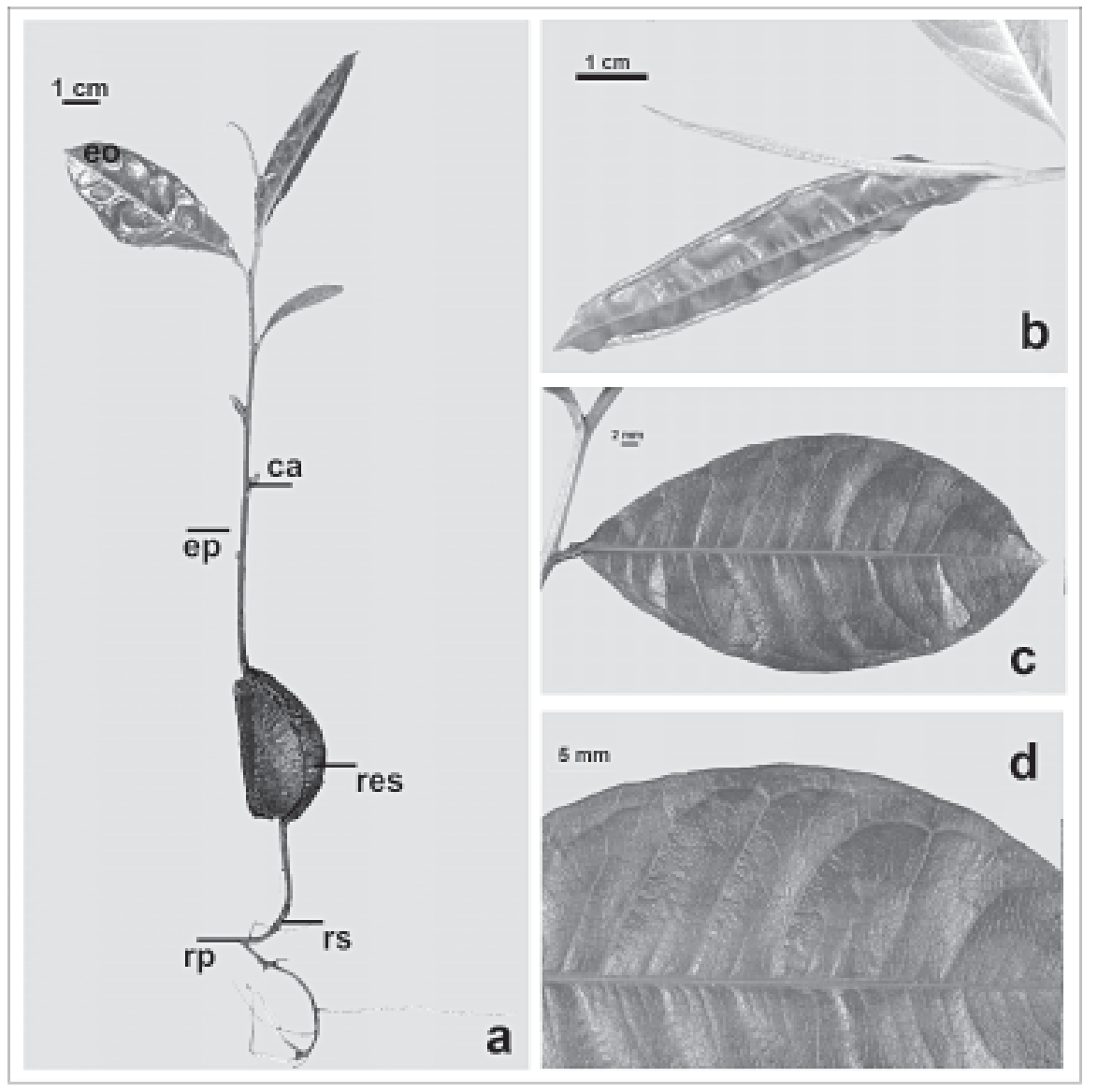

Figura 4. Bertholletia excelsa Humboldt \& Bonpland . Detalhes da plântula: a) hábito; b) prefolheação involuta dos eófilosl; c) face abaxial do eófilo; d) eófilo em face adaxial. ca-catáfilo; ep-epicótilo; res-restos seminais; rp-raiz principal; rs-raiz secundária.

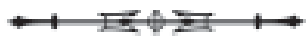


Vale ressaltar que o tipo carpológico pixídio classificado por Moritz (1984) e Cavalcante (1996), segundo Barroso et al. (1999), é originado de ovário súpero ou ínfero, com deiscência transversal, dividindo o fruto em duas porções distintas, o que não ocorre com $B$. excelsa.

No fruto da espécie aqui estudada, atribui-se a denominação cápsula poricida simples, indeiscente (por não liberar as sementes espontaneamente), de acordo com a classificação de Barroso et al. (1999), devido às características morfológicas do fruto dessa espécie.

Prance e Mori (1979), estudando a morfologia do fruto de Bertholletia, afirmam que não foi observado funículo, porém, neste trabalho foi observado funículo de consistência lenhosa. Também Moritz (1984) cita que, nos quatro a cinco lóculos existentes, as sementes estão unidas, através do funículo, à coluna central do ovário.

Van Roosmalen (1985) e Oliveira e Daly (2001) caracterizam a dispersão de Bertholletia excelsa como sinzoocórica, identificando como dispersores os roedores, principalmente cutias (Agoutis), os quais removem as sementes roendo o pericarpo duro e lenhoso do fruto e, posteriormente, enterram algumas para refeições futuras, permitindo, assim, quando esquecidas, a germinação das mesmas.

Müller (1995) caracteriza o aspecto morfológico das sementes da castanha-do-pará como de formato triangular anguloso, casca bastante dura e rugosa, com pólo radicular (base da semente), de onde se origina a raiz primária, mais largo que o caulicular, o qual origina a parte aérea da planta. Neste estudo, além destas características, também foram evidenciadas outras na semente de Bertholletia, como posição axial da semente no fruto, trisseriada, com testa lígnea, ausência de arilo ou arilóide, sendo que estes últimos, segundo Barroso et al. (1999), são visualizados em várias sementes da familia das Lecythidaceae.
O embrião de Bertholletia excelsa é atípico. De acordo com Barroso et al. (1999), apresenta-se conferruminado, com estruturas ovóides, elipsóides, globosas, obovóides ou claviformes, sem distinção de cotilédones, nem do eixo hipocótilo-radícula. Mori e Prance (1990) denominam embrião indiferenciado, retido no interior da testa.

No presente estudo também foi observado o embrião sem distinção de cotilédones, concordando, assim, com Barroso et al. (1999).

Cavalcante (1996) descreve o limbo de Bertholletia na planta adulta como oblongo ou elíptico oblongo, base aguda e ápice obtuso-arredondado, ligeiramente acuminado e margens onduladas. Neste trabalho, o limbo da plântula é obovóide, com base simétrica e atenuada, ápice agudo e margens levemente serreada. Percebe-se, assim, a diferença da estrutura (limbo) nas duas fases de desenvolvimento da espécie.

Bawa e Hadley (1990) fazem a descrição morfológica de cinco tipos de plântulas pertencentes à família das Lecithydaceae, existentes na Floresta de Gabon (África), classificando a germinação de Petersianthus macrocarpus (P. Beauv.) Liben como fanerocotilar, epigeal com cotilédones foliáceos, o que ressalta a grande diversidade dessa família, pois, a descrição da germinação de Bertholletia excelsa é bem diferenciada, classificada aqui como criptocotiledonar, hipógea e sem distinção de cotilédones.

Ribeiro et al. (1999) afirmam que os caracteres mais úteis para identificação das espécies ocorrentes na área de estudo, pertencentes a Lecythidaceae, são a forma de venação, broquidódromas ou eucampdódromas, o padrão do ritidoma e a cor da casca viva. Vale ressaltar que, em relação à venação, neste estudo, Bertholletia, na fase de plântula, é broquidódroma.

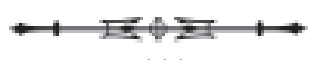




\section{REFERÊNCIAS}

BARROSO, G. M. 1999. Frutos e sementes: morfologia aplicada à sistemática de dicotiledôneas. Viçosa: Editora UFV, Universidade Federal de Viçosa. 443 p.

BAWA, K. S.; HADLEY, M. 1990. Reproductive ecology of tropical forest plants. Man and the biosphere series, v. 7, p. 3-12.

CAVALCANTE, P. B. 1996. Frutas comestíveis da Amazônia. 6. ed. Belém: CNPq, Museu Paraense Emilio Goeldi. 279 p. (Coleção Adolpho Ducke).

DUKE, J. A. 1965. Keys for the identification of seedlings of some proeminent woody species in eight forest types in Puerto Rico. Ann. Missouri Bot. Gard., v. 52, n. 3, p. 314-350.

DUKE, J. A. 1969. On tropical tree seedlings, systems and systematics. Ann. Missouri Bot. Gard., v. 56, n. 2, p. 135-161

DUKE, J. A.; POLHILL, R. M. 1981. Seedlings of Leguminosae. In: POLHILL, R. M.; RAVEN, P. H. (Ed.). Advances in Legumes Systematics. v. 2. Garden, Kew, Richmond: Surrey, England, Royal Bot. p. $941-949$

FONT-QUER, P. 1965. Dicionário de Botânica. Barcelona: Labor. $1244 \mathrm{p}$.

GURGEL, E. S. C. 2000. Morfologia de frutos, sementes, germinação e plântulas de leguminosas presentes em uma vegetação de mata secundária na Amazônia Central. 160 f. Dissertação (Mestrado) - Universidade do Amazonas, Instituto Nacional de Pesquisas da Amazônia, Manaus.

KUNIYOSHI, Y. S. 1983. Morfologia da semente e da germinação de 25 espécies arbóreas de uma floresta com araucária. 232 f. Dissertação (Mestrado) - Universidade Federal do Paraná, Curitiba, Paraná

LE COINTE, P. 1947. Amazônia Brasileira: árvores e Plantas Úteis. 2. ed. [S.l.]: Companhia Editora Nacional. v. 3. 506 p.

MARTIN, A. C. 1946. The comparative internal morphology of seeds. Am. Midl. Nat., v. 36, n. 3, p. 513-660

MORI, S. A.; PRANCE, G. T. 1990. Lecythidaceae: the zygomorphic-flowered New World Genera (Couropita, Corythophora, Bertholletia, Couratari, Eschweilera, e Lecythis). [S.1.:s.n.]. With a study of secondary xylem of Neotropical Lecythidaceae by Carl de Zeeuw. Part II. (FL. Neotrop. Monogr., 21)
MORITZ, A. 1984. Estudos biológicos da floração da Castanha-doBrasil (Bertholletia excelsa H.B.K.). Belém, Pará: EMBRAPA, CPATU. (Documentos, 29). $82 \mathrm{p}$.

MÜLLER, C. H. 1995. A cultura da castanha-do-brasil. Brasília: EMBRAPA-SPI. 65 p. Empresa Brasileira de Pesquisa Agropecuária. Centro de Pesquisa Agroflorestal da Amazônia Oriental. (Coleção Plantar, 23).

OLIVEIRA, E. C. 1993. Morfologia de plântulas florestais. In: AGUIAR, I. B.; PIÑA-RODRIGUES, F. C. M.; FIGLIOLA, M. B. (Ed.). Sementes florestais tropicais. Brasília: ABRATES. p. 175-214.

OlVEIRA, A. A. de; DALY, D. C. 2001. Florestas do Rio Negro. São Paulo: Editora Científica, Companhia das Letras.

PRANCE, G. T.; MORI, S. A. 1979. The actinomorphic-flowered New World Lecythidaceae. Lecythidaceae. p. 1-270. Part I. (Fl. Neotrop. Monogr., 21).

RADFORD, A. E. et al. 1974. Vascular plants systematics. New York: Harper and Row. 877 p.

RIBEIRO, J. E. L. S. et al. 1999. Flora da reserva Ducke: guia de identificação de plantas vasculares de uma floresta de terra-firme na Amazônia Central. Manaus: INPA. 816 p.

RODERJAN, C. V. 1983. Morfologia do estádio juvenil de 24 espécies arbóreas de uma floresta com araucária. 148 f. Dissertação (Mestrado) - Universidade Federal do Paraná, Curitiba, Paraná

SILVA, M. F. da; Lisboa, P. L. B.; Lisboa, R. C. L. 1977. Nomes Vulgares de Plantas Amazônicas. Belém: INPA. 222 p.

STERN, W. T. 1992. Botanical latin. history, grammar, syntax, terminology and vocabulary. New York: Ed. Hafner Publishing Company. 566 p.

SYSTEMATICS ASSOCIATION COMMITTEE FOR DESCRIPTIVE TERMINOLOGY. 1962. Terminology of simple symmetrical plane shapes (chart 1). [S.l.:s.n.]. p. 104-109. (Taxon, 9).

VAN DER PIJL, L. 1972. Principles of dispersal in higher plants. Berlin: Springer Verlag. $162 \mathrm{p}$

VAN ROOSMALEN, M. G. M. 1985. Fruits of the Guianan Flora. Neetherlands: Utretcht Institute of Systematic Botany, Utretcht University. 483 p. 